\title{
TAK242 suppresses the TLR4 signaling pathway and ameliorates DCD liver IRI in rats
}

\author{
XIANG ZHONG $^{1 *}$, QI XIAO ${ }^{*}$, ZHONGZHONG LIU ${ }^{2}$, WEI WANG $^{2}$, CHIN-HUI LAI $^{2}$, \\ WANG YANG ${ }^{2}$, PENGPENG YUE ${ }^{2}$, QIFA YE ${ }^{2,3}$ and JIANSHENG XIAO ${ }^{1}$ \\ ${ }^{1}$ Department of General Surgery, The First Affiliated Hospital of Nanchang University, Nanchang, Jiangxi 330006; \\ ${ }^{2}$ Department of Hepatobiliary Diseases, Zhongnan Hospital of Wuhan University, Wuhan, Hubei 430071; \\ ${ }^{3}$ Department of Transplant Surgery, The Third Xiangya Hospital of Central South University, \\ Changsha, Hunan 410013, P.R. China
}

Received November 17, 2018; Accepted April 30, 2019

DOI: $10.3892 / \mathrm{mmr} .2019 .10439$

\begin{abstract}
Ischemia-reperfusion injury (IRI) is a notable cause of tissue damage during surgical procedures and a major risk factor in graft dysfunction in liver transplantation. Livers obtained from donors after circulatory death (DCD) are prone to IRI and toll-like receptor 4 (TLR4) serves a prominent role in the inflammatory response associated with DCD liver IRI. The present study was designed to investigate whether TAK242, a specific TLR4 inhibitor, improves hepatic IRI following a DCD graft and to investigate its underlying protective mechanisms. Male Sprague-Dawley rats were randomized into 4 groups: Control, TAK242, DCD and DCD+TAK242 groups. Rats were pretreated with TAK242 or its vehicle for $30 \mathrm{~min}$, then the livers were harvested without warm ischemia (control group and TAK242 group) or with warm ischemia in situ for $30 \mathrm{~min}$. The livers were stored in cold University of Wisconsin solution for $24 \mathrm{~h}$ and subsequently perfused for $60 \mathrm{~min}$ with an isolated perfused rat liver system. Rat liver injury was evaluated thereafter. When compared with the DCD group, DCD livers with TAK242 pretreatment displayed significantly improved hepatic tissue injury and less tissue necrosis $(\mathrm{P}<0.05)$. Compared with DCD livers, mechanistic experiments revealed that TAK242 pretreatment alleviated mitochondrial dysfunction, reduced reactive
\end{abstract}

Correspondence to: Dr Jiansheng Xiao, Department of General Surgery, The First Affiliated Hospital of Nanchang University, 17 Yongwai Zhengjie Street, Nanchang, Jiangxi 330006, P.R. China E-mail: super_xiaoj@163.com

Professor Qifa Ye, Department of Hepatobiliary Diseases, Zhongnan Hospital of Wuhan University, 169 Donghu Road, Wuhan, Hubei 430071, P.R. China

E-mail: yqf_china@163.com

\section{${ }^{*}$ Contributed equally}

Key words: donors after circulatory death, ischemia-reperfusion injury, toll-like receptor 4, TAK242 oxygen species and malondialdehyde levels and inhibited apoptosis. Additionally, TAK242 significantly inhibited the IRI-associated inflammatory response, indicated by the decreased expression of TLR4, interleukin (IL)-1 $\beta$, IL-6 and cyclooxygenase 2 at the mRNA and protein levels $(\mathrm{P}<0.05)$. TAK242 ameliorates DCD liver IRI via suppressing the TLR4 signaling pathway in rats. The results of the present study have revealed that TAK 242 pretreatment harbors a potential benefit for liver transplantation.

\section{Introduction}

Liver transplantation remains at present an effective treatment for patients with end-stage liver disease. Due to the increasing disparity between the number of patients on the waiting list and the number of donor organs available (1), the use of livers from donors after circulatory death (DCD) has been deemed to be a useful strategy to overcome organ shortage $(2,3)$. However, compared with the recipients of livers from donors after brain death, patients who receive DCD liver transplantation have worse prognoses (3). Additionally, the incidence of biliary complications and retransplantation is increasing in the recipients of DCD livers (4). The notable factor resulting in the poor outcome of patients with DCD liver grafts is ischemia-reperfusion injury (IRI) (5).

Hepatic IRI results from the combined effect of multiple pathological responses occurring during ischemia and reperfusion processes (6). As livers from DCD donors endure an unpredictable duration of warm ischemia, they are more susceptible to IRI $(6,7)$. Presently, IRI has been established to be one of the primary reasons for post-transplantation complications including chronic graft rejection and primary graft nonfunction (8). The pathological characteristics of IRI include an reactive oxygen species (ROS) overabundance, mitochondrial dysfunction and sodium-potassium pump failure $(9,10)$. A combination of mitochondrial dysfunctions in the ischemia phase and the activation of innate immunity in the reperfusion phase result in a deterioration in organ function $(11,12)$. Among the notable molecular events implicated in IRI, an excessive innate inflammatory response has attracted particular attention. Damage associated molecular 
patterns released from the stressed cells bind to pattern recognition receptors (PRRs), resulting in the activation of innate immune cells $(12,13)$. Toll-like receptor 4 (TLR4) have been hypothesized to have a pivotal function in harmful, aseptic inflammation (13). Therefore, the present study hypothesized that inhibiting the TLR4 signaling pathway in DCD livers may reduce tissue reperfusion-induced inflammation and accordingly improve the quality of DCD grafts.

A number of clinical approaches are presently being applied to minimize IRI, including ischemia pretreatment (IPC), normothermic mechane perfusion and hypothermic mechane perfusion $(14,15)$. Radojkovic et al $(16)$ revealed that IPC exerts a protective effect on IRI by reducing oxidative stress and inflammation in vivo. Mergental et al (17) reported that normothermic machine perfusion increases organ availability for liver transplantation. Nevertheless, it is difficult to apply these approaches on a wider scale due to the complicated techniques involved. Comparatively, pharmacological manipulations of those necessary signaling pathways are a promising strategy to reduce liver IRI (15). TAK242 is a specific inhibitor of the TLR4 signaling pathway (18). It has been reported that TAK242 ameliorates tissue injury by dampening the innate immune response (19). However, so far it is unclear whether TAK242 may alleviate IRI in the DCD grafts by inhibiting the TLR4 signaling pathway.

In the present study, the effects of TAK242 on the TLR4 signaling pathway, inflammatory cytokine release and tissue damage were evaluated using a rat DCD model. It was hypothesized that TAK242 ameliorates hepatic IRI and resultantly improves the quality of DCD grafts via reducing the release of pro-inflammatory cytokines and inhibiting the excessive innate immune response. The present study aimed to determine the effectiveness of the TLR4 inhibitor in reducing liver IRI and improving the quality of DCD grafts.

\section{Materials and methods}

Animals. The present experiment was conducted with the ethical approval of the Animal Experimental Ethics Committee of Wuhan University (Wuhan, China) and all experimental procedures were performed in accordance with the Guidance for the Care and Use of Laboratory Animals (20). A total of 24 male Sprague-Dawley (SD) rats (weighing 250-300 g) were purchased from Beijing Vital River Laboratory Animal Technology Co., Ltd. (Beijing, China) and maintained at $22-24^{\circ} \mathrm{C}$, with a 12 -h light/dark cycle and ad libitum access to food and water.

Experimental design. Rats were randomly divided into 4 groups ( $\mathrm{n}=6$ each), and all rats were fasted for $12 \mathrm{~h}$ prior to the initiation of the experimental procedures (but without drinking restrictions). For the control group, the rats were pretreated with intraperitoneal injections of $0.1 \%$ dimethyl sulfoxide (DMSO) as the vehicle for $30 \mathrm{~min}$ prior to the surgical operations, and then anesthetized with pentobarbital sodium (50 mg/kg intraperitoneally) and the livers without warm ischemia exposure were obtained by midline laparotomy, followed by $24 \mathrm{~h}$ storage at $4^{\circ} \mathrm{C}$ in University of Wisconsin (UW) solution (DowDuPont, Inc.). Subsequently, the livers were connected to an isolated perfused rat liver system (IPRL) and perfused at $37 \pm 0.5^{\circ} \mathrm{C}$ for $1 \mathrm{~h}$. For the TAK242 group, TAK242 was dissolved in DMSO and diluted with physiological saline. Doses of TAK-242 were determined based on preliminary tests (using $0.1,0.5$ and $1.0 \mathrm{mg} / \mathrm{kg}$ ) and on previous studies $(18,21)$. The preliminary tests revealed that 0.5 and $1.0 \mathrm{mg} / \mathrm{kg}$ TAK-242 induced protective effects in DCD livers, and that $1.0 \mathrm{mg} / \mathrm{kg}$ TAK-242 was more effective. The rats were pretreated with an intraperitoneal injection of TAK242 $(1.0 \mathrm{mg} / \mathrm{kg})$ at $37^{\circ} \mathrm{C}$ for $30 \mathrm{~min}$ prior to all surgical operations and all other operations were performed consistent with the control group. For the DCD group, the livers were subjected to in situ warm ischemia at $37^{\circ} \mathrm{C}$ for $30 \mathrm{~min}$, but all other operations were performed in the same manner as in the control group. For the DCD+TAK242 group, the rats were pretreated with TAK242 $(1.0 \mathrm{mg} / \mathrm{kg})$ at $37^{\circ} \mathrm{C}$ for $30 \mathrm{~min}$, as previously described (22), but all other procedures were similar between the DCD+TAK242 group and the DCD group.

DCD model and liver procurement. Following midline laparotomy, cardiac arrest was induced by an incision of the diaphragm (23), and simultaneously, curved vascular clamping was used to prevent blood flow in the thoracic aorta. Following $30 \mathrm{~min}$ of warm ischemia at $37^{\circ} \mathrm{C}$, the livers were perfused with $40 \mathrm{ml}$ cold heparinized Ringer's solution (Shanghai Guandao Biological Engineering Co., Ltd.) via the aorta abdominalis. Subsequently, the portal vein and infrahepatic vena cava were cannulated with polyethylene pipes, followed by the ligation of the superior hepatic caval and the right adrenal veins. The rats in the control group underwent the same procedure but with an absence of warm ischemia.

IPRL system. Following cold storage, the livers were connected to the IPRL system and subjected to normothermic perfusion for $60 \mathrm{~min}$ at $37 \pm 0.5^{\circ} \mathrm{C}$, as previously described (24). The IPRL system was based on previously described methods (24). Freshly prepared Krebs-Henseleit bicarbonate buffer (Sigma-Aldrich; Merck KGaA) with $95 \% \mathrm{O}_{2}$ and $5 \% \mathrm{CO}_{2}$ was pumped into the liver via the portal vein with a peristaltic pump (Shanghai Jingke Industrial Co., Ltd.). The flow velocity of the perfusate was set at a flow rate of $15 \mathrm{ml} / \mathrm{min}$. To ensure that portal pressure did not exceed $8 \mathrm{mmHg}$, pressure sensors (Chengdu Techman Software Co., Ltd.) were used to monitor portal pressure. The perfusate was serially collected from the intrahepatic vena at 5,30 and $60 \mathrm{~min}$. Following perfusion, the perfusate and tissue samples were stored at $-80^{\circ} \mathrm{C}$ for later analyses.

Measurement of perfusate aminotransferase. The perfusates were stored in a refrigerator at $-80^{\circ} \mathrm{C}$ for $24 \mathrm{~h}$ and tested after all liver perfusions have been completed. The levels of alanine aminotransferase (ALT) and aspartate aminotransferase (AST) in the perfusate were determined using an automatic biochemical analyzer (Hitachi, Ltd., Tokyo, Japan) in the clinical laboratory of Zhongnan Hospital of Wuhan University.

Histopathology and terminal deoxynucleotidyl-transferase-mediated dUTP nick end labelling (TUNEL) assay. Liver samples were sliced into small pieces following $1 \mathrm{~h}$ of perfusion and were fixed in $4 \%$ buffered paraformaldehyde at room temperature for $24 \mathrm{~h}$, embedded in paraffin at $60^{\circ} \mathrm{C}$ 
for $1 \mathrm{~h}$ and stained with haemotoxylin and eosin (H\&E) at room temperature for $10 \mathrm{~min}$. The severity of liver IRI was blindly graded according to Suzuki's criteria (25). Briefly, the degree of sinusoidal congestion, vacuolization/ballooning and hepatocyte necrosis are graded on a scale from 0 to 4 (25). Histopathological changes were evaluated by two pathologists who were blinded to this experiment. Paraffin-embedded tissue sections were examined for apoptosis using a TUNEL staining assay (Roche Diagnostics, Indianapolis, IN, USA) according to the manufacturer's protocol and tissue sections were incubated with fluorescein-dUTP at $37^{\circ} \mathrm{C}$ for $1 \mathrm{~h}$. Total hepatocytes and TUNEL-positive cells were counted in 6 randomly selected fields of view, and the apoptotic index (the percentage of apoptotic cells in all hepatocytes in each view) was calculated with the use of Image-Pro Plus 6.0 (Media Cybernetics, Inc., Rockville, MD, USA).

Immunohistochemistry and immunofluorescence. The protein expression levels of high-mobility group box protein b1 (HMGB1) and TLR4 in liver tissues were analyzed by immunohistochemistry using polyclonal rabbit primary antibodies and secondary polymeric horseradish peroxidase (HRP)-conjugated anti-rabbit immunoglobulin G ( $\mathrm{IgG}$ ) antibodies. Livers were fixed in $4 \%$ buffered paraformaldehyde at room temperature for $24 \mathrm{~h}$ and embedded in paraffin at $60^{\circ} \mathrm{C}$ for $1 \mathrm{~h}$. The paraffin-embedded liver tissues were cut into 3-4 $\mu \mathrm{m}$-thick sections. Sections were deparaffinized and rehydrated with a graded xylene and alcohol series. Antigen retrieval was performed by high temperature and pressure; $1 \mathrm{mM}$ EDTA (Beijing Solarbio Science \& Technology Co., Ltd.) was heated to $\sim 100^{\circ} \mathrm{C}$, the sections were soaked in EDTA and heated for $\sim 3-4 \mathrm{~min}$ at a pressure of $110 \mathrm{kPa}$. Sections were incubated in $3 \%$ hydrogen peroxide at room temperature for $10 \mathrm{~min}$. Subsequently, sections were blocked in $10 \%$ BSA (Beijing Solarbio Science \& Technology Co., Ltd.) at room temperature for $30 \mathrm{~min}$. Section were incubated with rabbit anti-HMGB1 (cat. no. 10829-1-AP; 1:100; ProteinTech Group, Inc.) or rabbit anti-TLR4 (cat. no. 19811-1-AP; 1:200; ProteinTech Group, Inc.) at $4^{\circ} \mathrm{C}$ overnight, and incubated with HRP-conjugated anti-rabbit IgG antibodies at room temperature for $30 \mathrm{~min}$ (cat. no. SA00001-2; 1:200; ProteinTech Group, Inc.). Sections were incubated with diaminobenzidine (Shanghai Yeasen Biotechnology Co., Ltd.) at room temperature for $5 \mathrm{~min}$. Subsequently, sections were stained using $1.5 \mathrm{mg} / \mathrm{ml}$ hematoxylin at room temperature for $2 \mathrm{~min}$. Sections were visualized using light microscopy (magnification, x200). HRP activity was measured using 3,3'-diaminobenzidine substrate. The expression of interleukin-6 (IL-6) in liver tissues was analyzed by immunofluorescence and eight fields of view were randomly selected to quantify IL-6 expression. Livers were fixed, embedded and sectioned using the same method mentioned above. Sections were blocked in 5\% BSA (Beijing Solarbio Science \& Technology Co., Ltd.) at room temperature for $2 \mathrm{~h}$ and were incubated with rabbit anti-IL-6 (cat. no. 21865-1-AP; 1:100; ProteinTech Group, Inc.) at $4^{\circ} \mathrm{C}$ overnight. The sections were then incubated with Alexa Fluor 555-conjugated goat anti-rabbit (cat. no. P0179; 1:100; Shanghai Biyuntian Biological Co., Ltd.) and DAPI at room temperature for $1 \mathrm{~h}$ (cat. no. C1002; Shanghai Biyuntian Biological Co., Ltd.). Results were visualized using a fluorescence microscope (magnification, $\mathrm{x} 400$ ) and images were analyzed by Image $\mathbf{J}$ software (version 1.51; National Institutes of Health).

Transmission electron microscopy (TEM). Tissues were cut into $1-2 \mathrm{~mm}$ sections and were fixed in $2.5 \%$ glutaraldehyde at $4^{\circ} \mathrm{C}$ for $24 \mathrm{~h}$. Subsequently, tissues were immersed in $1 \%$ osmium tetroxide at $4^{\circ} \mathrm{C}$ for $2 \mathrm{~h}$ and were dehydrated using a graded ethanol series. Later, tissue were embedded in Epon resin (Thermo Fisher Scientific, Inc.) at $60^{\circ} \mathrm{C}$ for $36 \mathrm{~h}$. Tissues were cut into sections (thickness, $\sim 70 \mathrm{~nm}$ ) using a microtome (Leica Microsystems Inc.) and stained with uranylacetate and lead citrate. The extent of liver IRI was evaluated by observing damaged subcellular organelles under a TEM (Tecnai G2 20 TWIN; FEI; Thermo Fisher Scientific, Inc., Waltham, MA, USA), performed by the Wuhan Institute of Virology, Chinese Academy of Sciences (Wuhan, China). The severity of mitochondrial damage was blindly graded according to Flameng criteria which evaluates mitochondrial function based on mitochondrial morphology and grades this on a scale from 0 to 4 (26).

Reverse transcription-quantitative polymerase chain reaction $(R T-q P C R)$. Total RNA from liver tissues was extracted using TRIzol reagent (Invitrogen; Thermo Fisher Scientific, Inc.) and RNA was reverse transcribed into cDNA using the RevertAid First Strand cDNA Synthesis Kit (Thermo Fisher Scientific, Inc.). RT was performed at $42^{\circ} \mathrm{C}$ for $1 \mathrm{~h}$ followed by an incubation at $75^{\circ} \mathrm{C}$ for $5 \mathrm{~min}$. cDNA was separated by $1 \%$ agarose gel electrophoresis. The thermocycling conditions were as follows: $50^{\circ} \mathrm{C}$ for $2 \mathrm{~min}, 95^{\circ} \mathrm{C}$ for $10 \mathrm{~min}$, followed by 40 cycles of $95^{\circ} \mathrm{C}$ for $10 \mathrm{sec}$ and $60^{\circ} \mathrm{C}$ for $30 \mathrm{sec}$. The relative quantity of the assessed genes to the housekeeping gene were analyzed using the SYBR green PCR Master Mix (Thermo Fisher Scientific Inc.) according to the manufacturer's protocol, and performed on a SYBR green quantitative RealTime-PCR system (Yeasen Biotechnology Co., Ltd., Shanghai, China). The relative expression of genes was calculated using the $2^{-\Delta \Delta C q}$ method and $\beta$-actin was used as internal standard (27). Primers used are listed in Table I.

Western blot analysis. Frozen liver tissues were disrupted in phenylmethylsulfonyl fluoride (Roche Applied Science, Penzberg, Germany)-containing RIPA lysis buffer (Beyotime Institute of Biotechnology, Haimen, China) using a tissue lyser, followed by centrifugation $\left(24,000 \mathrm{x} \mathrm{g}\right.$ for $15 \mathrm{~min}$ at $\left.4^{\circ} \mathrm{C}\right)$. Following heat denaturation, Protein concentration was determined using a bicinchoninic acid assay kit (Beyotime Institute of Biotechnology). An equal amount of protein $(50 \mu \mathrm{g})$ was separated on 10\% SDS-PAGE gels, followed by an electrotransfer onto PVDF membranes. Subsequent to blocking in $5 \%$ bovine serum albumin at room temperature for $2 \mathrm{~h}$, the immunoblots were incubated with primary antibodies at $4^{\circ} \mathrm{C}$ overnight, followed by incubation with the secondary HRP-conjugated anti-rabbit IgG antibody (cat. no. SA00001-2; 1:8,000; ProteinTech Group, Inc.) for $2 \mathrm{~h}$ at room temperature. All primary and secondary antibodies were from ProteinTech Group, Inc. (Chicago, IL, USA) and include rabbit anti-HMGB1 (cat. no. 10829-1-AP; 1:1,000; ProteinTech Group, Inc.), rabbit anti-TLR4 (cat. no. 19811-1-AP; 1:1,000; ProteinTech Group, Inc.), rabbit anti-IL-1 $\beta$ (cat. no. 16806-1-AP; 1:500; 
Table I. Nucleotide sequences of primers used for reverse transcription-quantitative polymerase chain reaction.

\begin{tabular}{|c|c|c|}
\hline Gene & & Primer sequence $\left(5^{\prime}-3^{\prime}\right)$ \\
\hline \multirow[t]{2}{*}{ HMGB1 } & Forward & GGCGGCTGTTTTGTTGACAT \\
\hline & Reverse & ACCCAAAATGGGCAAAAGCA \\
\hline \multirow[t]{2}{*}{ TLR4 } & Forward & TGTATCGGTGGTCAGTGTGC \\
\hline & Reverse & CAGCTCGTTTCTCACCCAGT \\
\hline \multirow[t]{2}{*}{ IL-1 $\beta$} & Forward & GAGGCTGACAGACCCCAAAAGA \\
\hline & Reverse & TCCACAGCCACAATGAGTGACA \\
\hline \multirow[t]{2}{*}{ IL-6 } & Forward & AGCGATGATGCACTGTCAGA \\
\hline & Reverse & GGAACTCCAGAAGACCAGAGC \\
\hline \multirow[t]{2}{*}{ TNF- $\alpha$} & Forward & GTGATCGGTCCCAACAAGGA \\
\hline & Reverse & TTTGCTACGACGTGGGCTAC \\
\hline \multirow[t]{2}{*}{$\mathrm{COX} 2$} & Forward & TCCATTTGTGAAGATTCCTGTGTTG \\
\hline & Reverse & TCTCACTGGCTTATGCCGAAA \\
\hline \multirow[t]{2}{*}{$\beta$-actin } & Forward & TGCTATGTTGCCCTAGACTTCC \\
\hline & Reverse & GTTGGCATAGGTCTTTACGG \\
\hline
\end{tabular}

$H M G B 1$, high-mobility group box protein b1; TLR4, toll-like receptor 4; IL, interleukin; COX2, mitochondrially encoded cytochrome c oxidase II; $T N F-\alpha$, tumor necrosis factor- $\alpha$.

ProteinTech Group, Inc.), rabbit anti-IL-6 (cat. no. 21865-1-AP; 1:500; ProteinTech Group, Inc.), rabbit anti-mitochondrially encoded cytochrome c oxidase II (COX2; cat. no. 12375-1-AP; 1:500; ProteinTech Group, Inc.) and rabbit anti- $\beta$-actin (cat. no. 20536-1-AP; 1:1,000; ProteinTech Group, Inc.). The bands were visualized using enhanced chemiluminescent reagent (Wuhan Boster Biological Technology, Ltd.) and quantified by using the Image-J software (version 1.51; National Institutes of Health).

Malondialdehyde (MDA) and ROS assays. To evaluate oxidative stress and lipid peroxidation, the levels of MDA and ROS were measured using commercial colorimetric assay kits (Nanjing Jiancheng Bioengineering Institute, Nanjing, China) according to the manufacturer's protocol.

Statistical analysis. Data were analyzed using SPSS 15.0 statistical software (SPSS, Inc., Chicago, IL, USA) and the results are expressed as the mean \pm standard deviation. Differences between groups were analyzed using a one-way analysis of variance followed by a Kruskal-Wallis test. $\mathrm{P}<0.05$ was considered to indicate a statistically significant difference.

\section{Results}

Effect of TAK242 on the function and pathology of DCD livers. First, the present study determined the leakage of ALT and AST into the liver perfusate, which are indicative of DCD liver injury and altered metabolic functions. As presented in Fig. 1A and B, the levels of two transaminase in the perfusate were significantly increased at each time point assessed in the DCD group when compared with those in the control group $(\mathrm{P}<0.05)$. There was no statistically significant difference in the level of transaminases between the control group and the TAK242 group ( $\mathrm{P}>0.05)$. However, TAK242 pretreatment for 30 min significantly decreased the levels of ALT and AST in the perfusate compared with those in the DCD group $(\mathrm{P}<0.05)$, suggesting that TAK242 pretreatment improves the metabolic functions of the DCD livers. H\&E staining revealed that there were significantly more infiltrated inflammatory cells and necrotic hepatocytes in the DCD group compared with in the control group, whereas they were significantly attenuated in the DCD+TAK242 group compared with the DCD group (Fig. 1D). Furthermore, the Suzuki scores, used for the assessment of liver damage and hepatocyte death (25), identified no statistically significant differences between the control group and the TAK242 group $(\mathrm{P}>0.05)$ but were significantly lower in the DCD+TAK242 group when compared with the DCD group $(\mathrm{P}<0.05$; Fig. 1C). These results indicate that pretreatment with TAK242 alleviates the IRI of the DCD livers.

Effect of TAK242 on oxidative stress and hepatocytic apoptosis in DCD livers. Next, the present study determined the redox status and hepatic apoptosis in the DCD livers pretreated with or without TAK242. When compared with the control group, the levels of ROS and MDA were not significantly different in the TAK242 group $(\mathrm{P}>0.05)$ but significantly increased in the DCD group $(\mathrm{P}<0.05)$, whereas these changes were significantly reversed following TAK242 pretreatment $(\mathrm{P}<0.05$; Fig. $2 \mathrm{~A}$ and $\mathrm{B})$, indicating an antioxidant effect of TAK242. Furthermore, as presented in Fig. $2 \mathrm{C}$ and D, the numbers of TUNEL-positive apoptotic cells in the DCD group were significantly increased compared with the control group, whereas a significant decrease in the numbers of apoptotic cells were observed in the DCD+TAK242 group compared with the DCD group $(\mathrm{P}<0.05)$. These results indicate that pretreatment with TAK242 attenuates oxidative stress and hepatocytic apoptosis in DCD livers.

Effect of TAK242 on the subcellular structure of the DCD livers. Next, the present study determined the subcellular structures of the DCD livers pretreated with or without TAK242 by TEM. As presented in Fig. 3A, when compared with the control group, the subcellular structure in group A was essentially normal without obvious changes, whereas the DCD group exhibited more serious damage to the subcellular structures, including the appearance of mitochondria swelling, nuclei irregularity, cellular edema and transparent electronic density area, whereas these structural changes, including mitochondrial damage and cellular edema, in the DCD livers were substantially relieved with the pretreatment with TAK242. As presented in Fig. 3B, the Flameng scores exhibited no statistically significant difference between the control group and the TAK242 group $(\mathrm{P}>0.05)$ but were significantly lower in the DCD+TAK242 group when compared with the DCD group $(\mathrm{P}<0.05)$. These results indicate that the TLR4 inhibitor protects DCD-exposed hepatocytes, partially via minimizing subcellular organelle damage.

Effect of TAK242 on TLR4 signaling pathway-associated mRNA expression of inflammatory mediators in the DCD livers. To understand the mechanism behind the protective effects of TAK242 on the DCD livers, the present study further determined the expression of HMGB1, TLR4 and their 

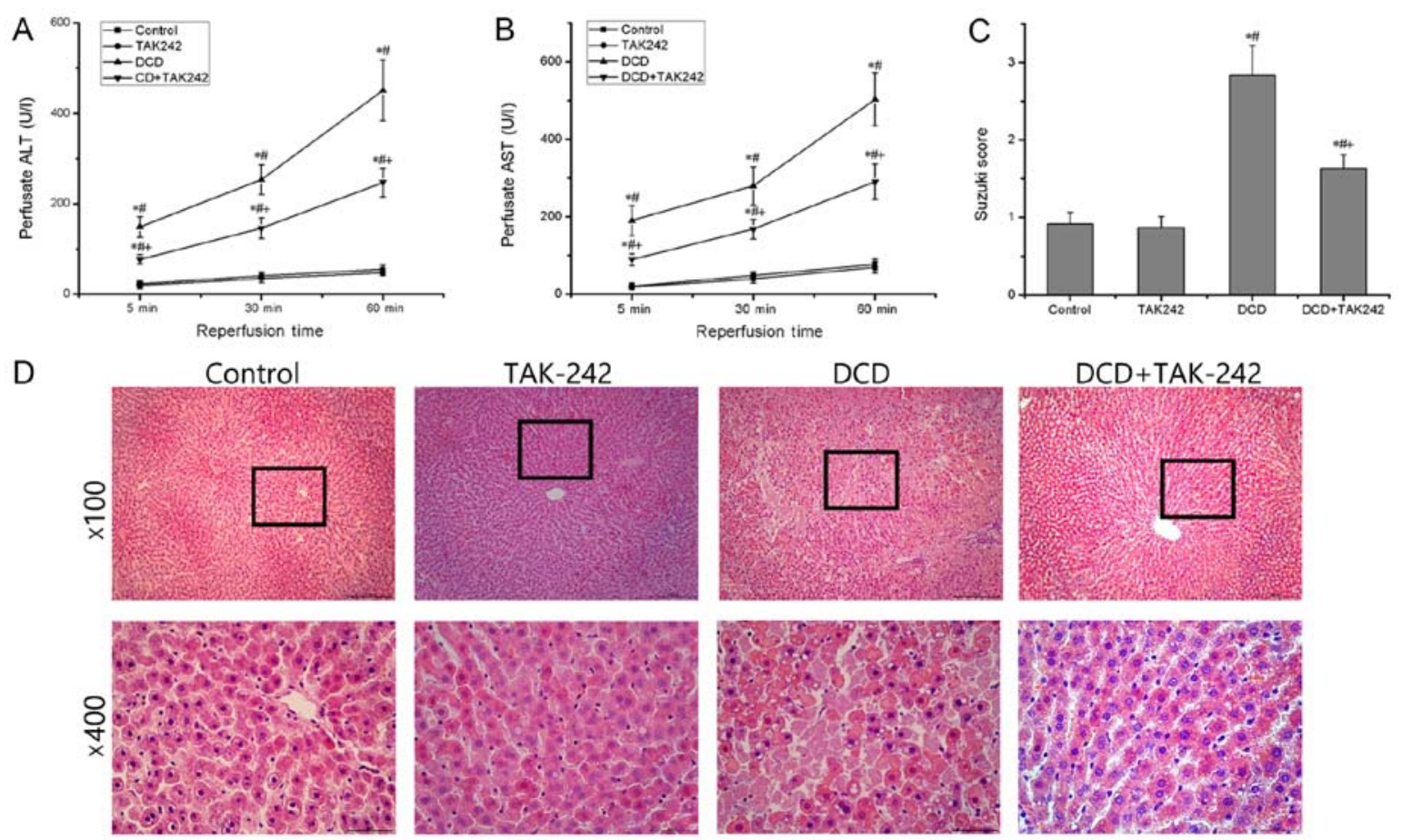

Figure 1. TAK242 pretreatment ameliorates hepatic tissue injury. Hepatic injury was evaluated by determining the release of ALT and AST into liver perfusate at different time points. (A) ALT levels of perfusate. (B) AST levels of perfusate. (C) Suzuki's criteria score of rat liver tissue in each group (n=6). (D) Haemotoxylin and eosin staining of rat liver tissues in each group $(\mathrm{n}=6)$. Magnification, $\mathrm{x} 100$ and $\mathrm{x} 400$. Data are expressed as the mean \pm standard deviation $(\mathrm{n}=6) .{ }^{*} \mathrm{P}<0.05$ vs. the control group. ${ }^{*} \mathrm{P}<0.05$ vs. the TAK242 group. ${ }^{+} \mathrm{P}<0.05$ vs. the DCD group. ALT, alanine aminotransferase; AST, aspartate aminotransferase; DCD, donors after circulatory death.
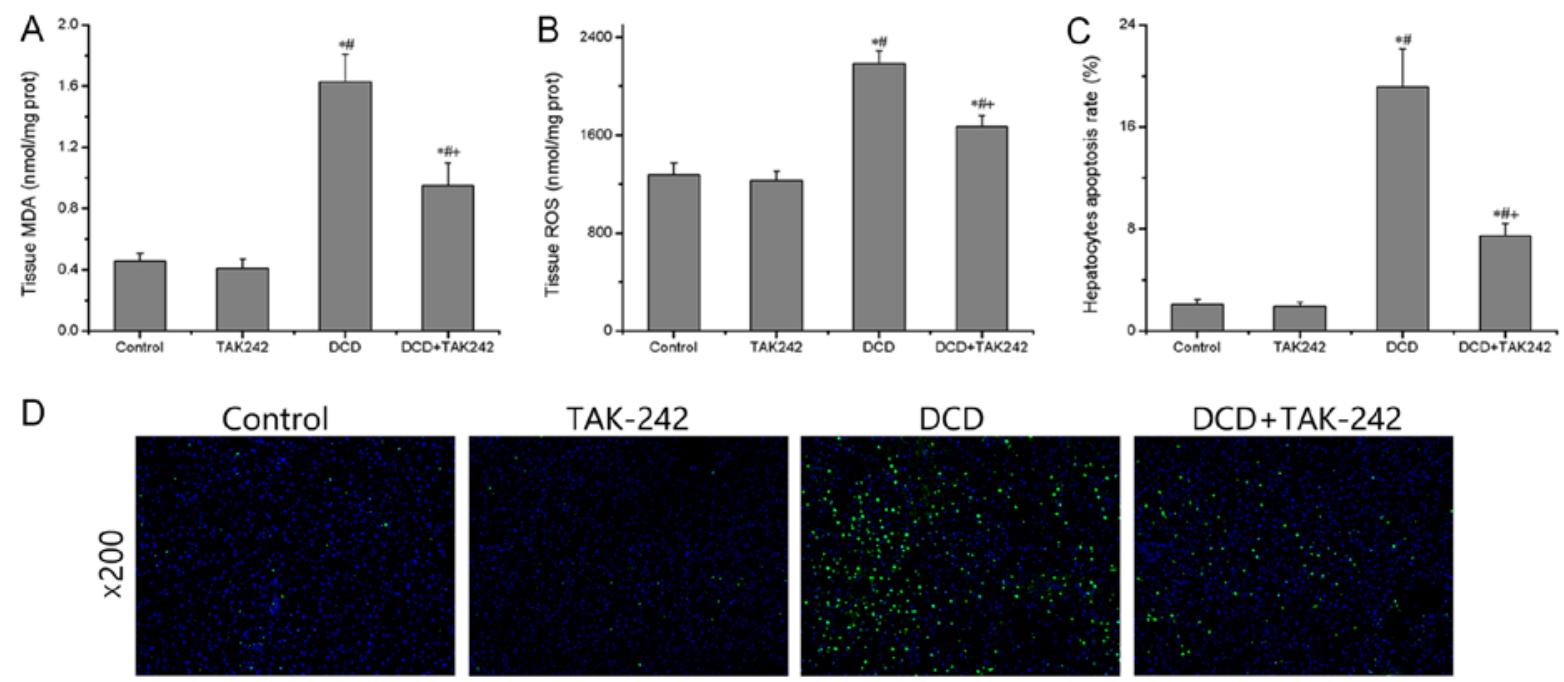

Figure 2. TAK242 pretreatment suppresses oxidative stress and apoptosis. (A) MDA levels in hepatic tissues. (B) ROS levels in hepatic tissues. (C) Quantitative analysis of liver apoptosis cells in each group $(\mathrm{n}=6)$. (D) Hepatocyte apoptosis; green dots indicate terminal deoxynucleotidyl-transferase-mediated dUTP nick end labelling-positive cells. Magnification, $\mathrm{x} 200$. Data are expressed as the mean \pm standard deviation. ${ }^{*} \mathrm{P}<0.05$ vs. the control group. ${ }^{*} \mathrm{P}<0.05$ vs. the TAK242 group. ${ }^{+} \mathrm{P}<0.05$ vs. the DCD group. MDA, malondialdehyde; ROS, reactive oxygen species; DCD, donors after circulatory death.

downstream target genes at the mRNA levels using RT-qPCR analysis. As presented in Fig. 4, it was revealed that TAK242 pretreatment, as expected, significantly inhibited the gene expression of TLR4, IL-1 $\beta$, IL-6, COX2 and tumor necrosis factor- $\alpha$ (TNF- $\alpha$ ) in comparison with the DCD-alone group $(\mathrm{P}<0.05)$. However, TAK242 did not significantly influence the gene expression of the cytokine HMGB1. These results support the concept that TAK242 inhibits the TLR4 signaling pathway and associated inflammation in DCD livers.
Effect of TAK242 on TLR4 signaling pathway-associated protein expression of inflammatory mediators in the $D C D$ livers. Next, the present study determined the effect of TAK242 on the expression of HMGB1, TLR4 and their downstream inflammatory mediators in DCD livers at the protein level using western blot analysis. As presented in Fig. 5, compared with the control group, TLR4 and their downstream inflammatory mediators did not change significantly in TAK242 group. But TAK242 pretreatment significantly downregulated the 

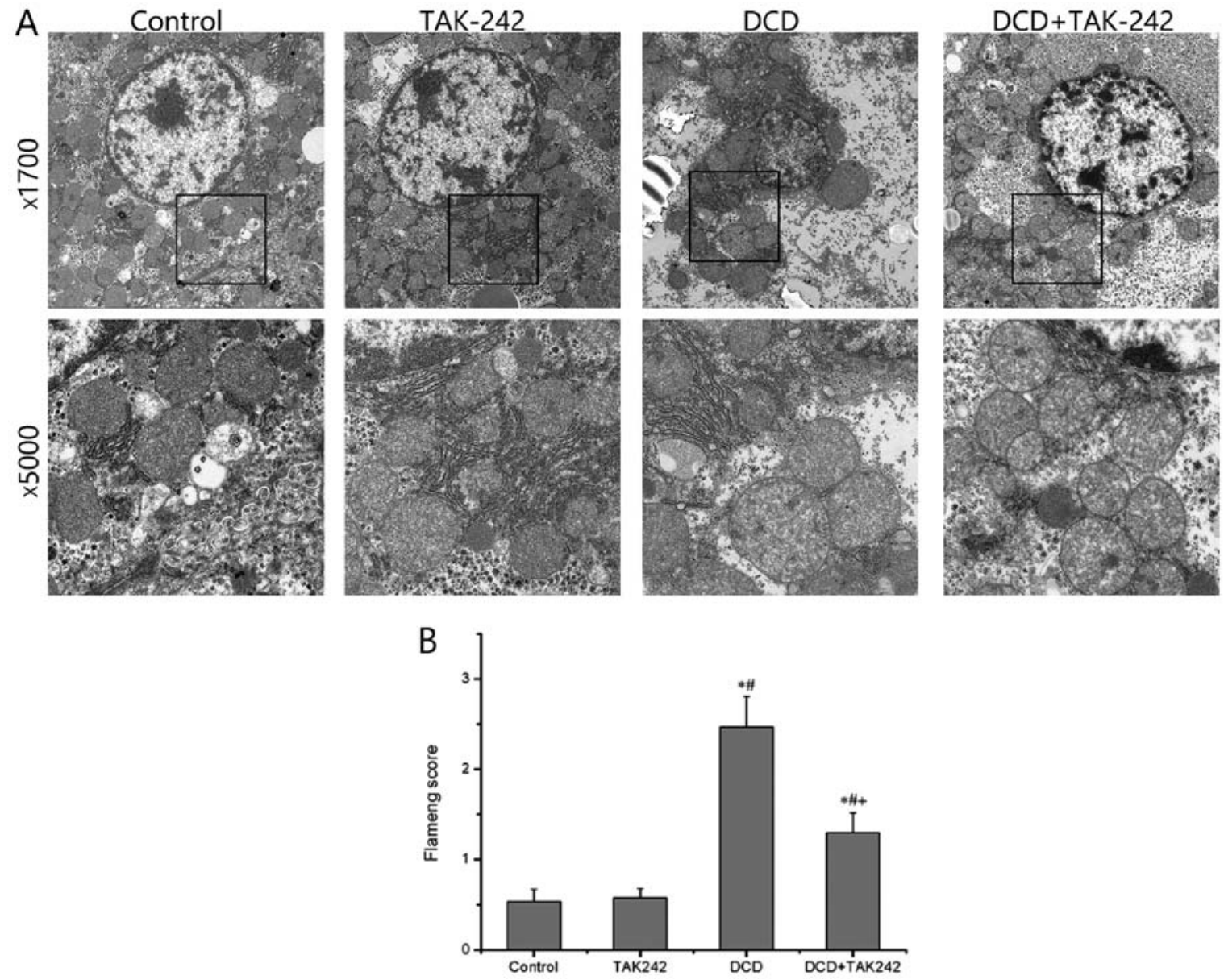

Figure 3. TAK242 pretreatment improves subcellular structure. (A) Transmission electron microscope examination of hepatocyte organelles. Magnification, $\mathrm{x} 1,700$ and $\mathrm{x} 5,000$. (B) Flameng score of mitochondrial damage in each group $(\mathrm{n}=6) .{ }^{*} \mathrm{P}<0.05$ vs. the control group. ${ }^{~} \mathrm{P}<0.05$ vs. the TAK 242 group. ${ }^{+} \mathrm{P}<0.05$ vs. the DCD group. DCD, donors after circulatory death.

protein expression levels of TLR4 and its downstream inflammatory mediators IL-1 $\beta$, IL-6 and COX2, compared with the DCD group $(\mathrm{P}<0.05)$. Again, there was no statistically significant difference in HMGB1 expression levels between the DCD group and the DCD+TAK242 group ( $\mathrm{P}>0.05)$. These results further confirmed that the TLR4 inhibitor, TAK242, reduces the production and expression of proinflammatory cytokines and enzymes in the DCD livers subjected to 24 -h cold storage and $1 \mathrm{~h}$ warm perfusion.

Finally, the present study demonstrated the downregulation of TLR4 in the DCD livers by immunohistochemical analysis. When compared with the control group, there were no significant changes in HMGB1 or TLR4 in the TAK242 group (Fig. 6A). There was no statistically significant difference in the percentage of HMGB1 and TLR4-positive cells between the TAK242 and the control group ( $\mathrm{P}>0.05$; Fig. 6B and C). The DCD groups exhibited a significantly increased expression of HMGB1 and TLR4 compared with the control group $(\mathrm{P}<0.05$; Fig. 6). TAK242 pretreatment in the DCD livers significantly decreased the percentage of TLR4 positive cells compared with the DCD group $(\mathrm{P}<0.05$; Fig. $6 \mathrm{C})$, However, TAK242 pretreatment in the DCD livers did not significantly decrease the percentage of HMGB1 positive cells compared with the DCD group (P>0.05; Fig. 6B). Immunofluorescence revealed that TAK242 pretreatment in DCD livers reduced the release of IL-6 when compared with the DCD group (Fig. 6D). These results further indicate that TAK242 reduces TLR4 expression in DCD livers.

\section{Discussion}

Hepatic IRI can cause tissue damage in liver surgery and transplantation, and affects graft regeneration, often resulting in a poor prognosis $(4,5,28)$. DCD livers which have experienced serious warm ischemia at the time of transplantation become particularly vulnerable to IRI $(9,10)$. Hepatic IRI may trigger an acute inflammatory response which further exacerbates graft injury (29). One previous study identified that TLR4 is a major PRR that mediates innate immune responses (30), so targeting TLR4 is considered to be effective in the reduction of graft injury in liver transplantation. As TAK242, a specific small molecular inhibitor of TLR4, has been under clinical development for the treatment of patients with severe inflammatory pathology (31), in the present study the use of the TLR4 inhibitor was extended to the improvement of hepatic IRI and graft quality. It was demonstrated that the TLR4 signaling pathway is activated by the state of circulatory death, whereas TAK 242 pretreatment improves the quality of the liver following reperfusion in rats, by inhibiting the TLR4 signaling pathway activation, inflammatory cytokine release, and redox stress. 

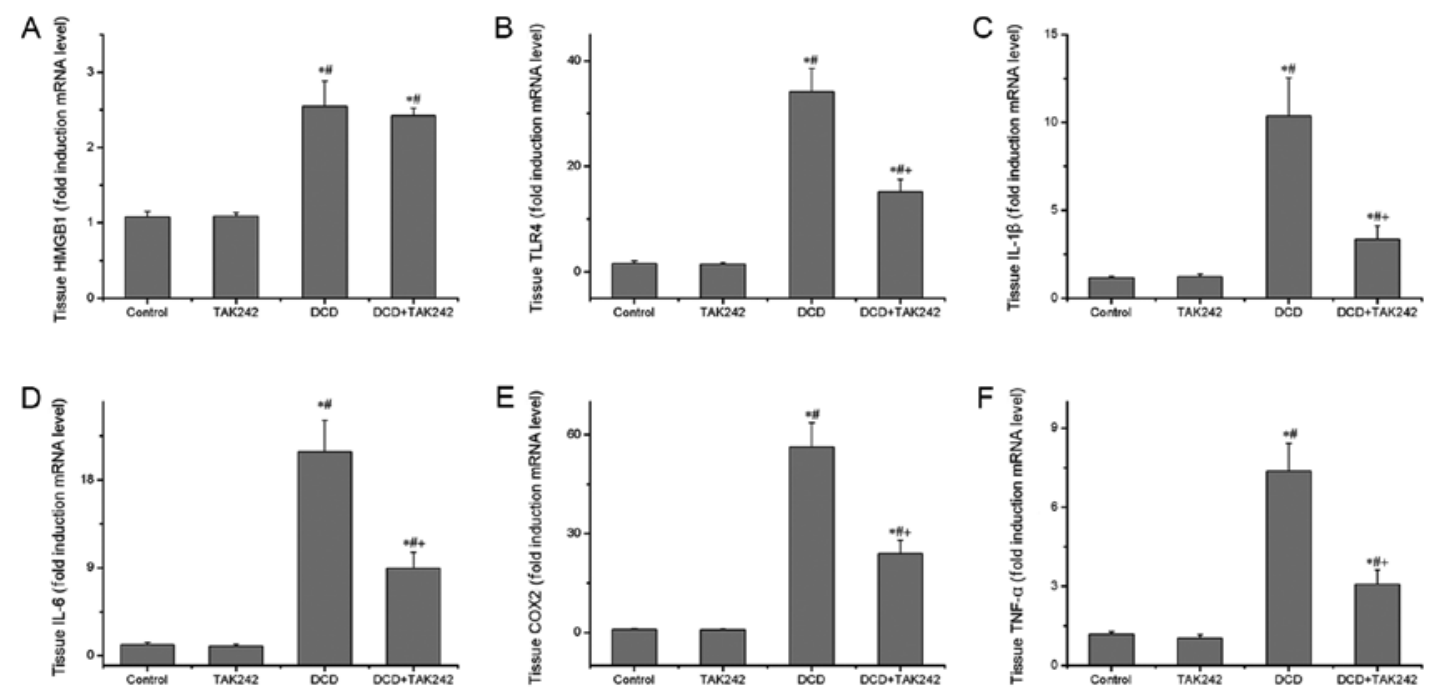

Figure 4. TAK242 pretreatment reduces the gene expression levels of HMGB1, TLR4 and TLR4 downstream target genes. The mRNA expression levels of (A) HMGB1, (B) TLR4, (C) IL-1 $\beta$, (D) IL-6, (E) COX2 and (F) TNF- $\alpha$ were assessed using reverse transcription-quantitative polymerase chain reaction. Three independent experiments were performed. Data are expressed as the mean \pm standard deviation. ${ }^{*} \mathrm{P}<0.05$ vs. the control group. ${ }^{~} \mathrm{P}<0.05$ vs. the TAK242 group. ${ }^{+} \mathrm{P}<0.05$ vs. the DCD group. DCD, donors after circulatory death; HMGB1, high-mobility group box protein b1; TLR4, toll-like receptor 4; IL, interleukin; COX2, mitochondrially encoded cytochrome $c$ oxidase II; TNF- $\alpha$, tumor necrosis factor- $\alpha$.

A
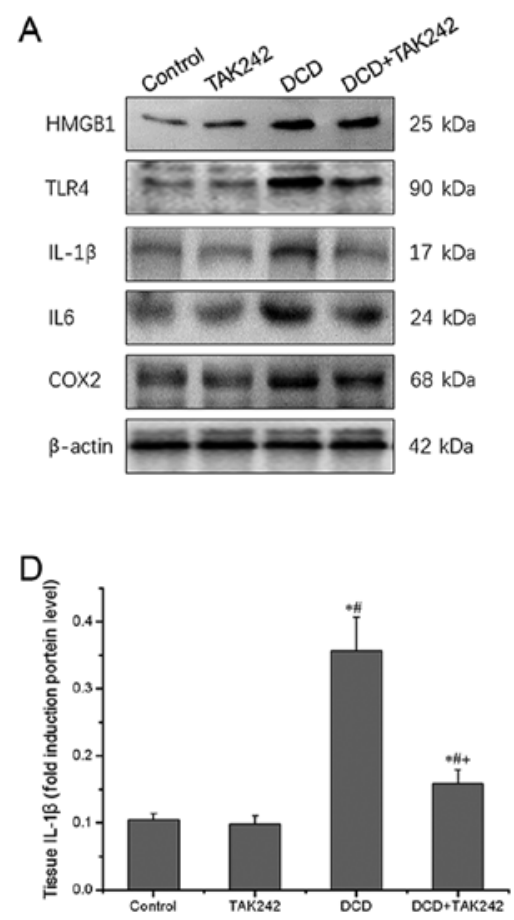

B

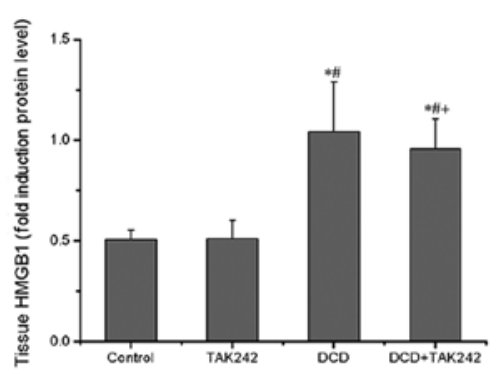

$\mathrm{E}$

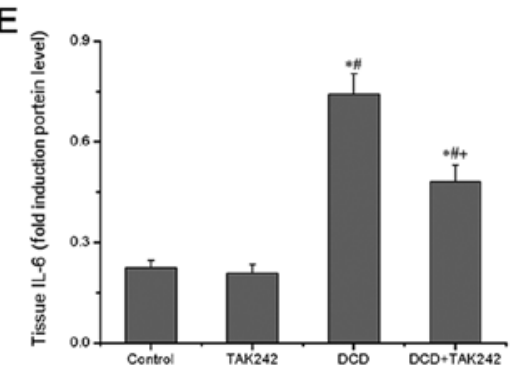

C
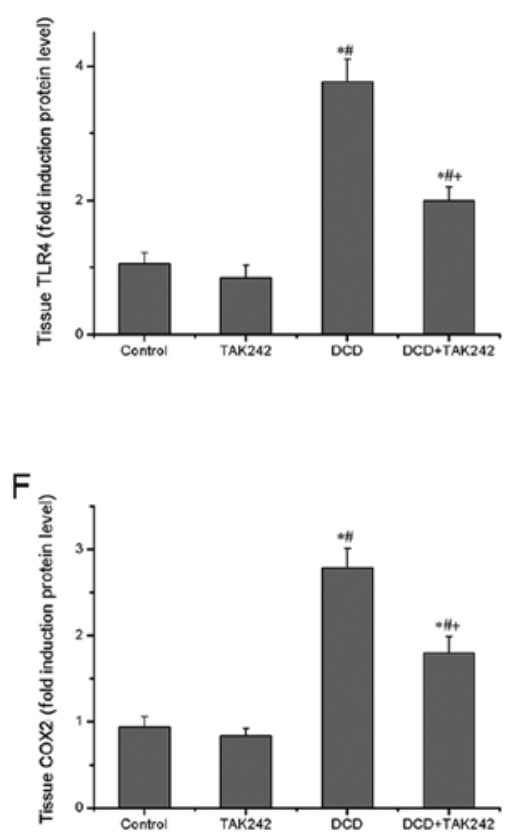

Figure 5. TAK242 pretreatment reduces the protein expression levels of HMGB1, TLR4 and TLR4 downstream target genes. (A) Western blot analysis of HMGB1, TLR4, IL-1 $\beta$, IL-6, COX2 and $\beta$-actin. Representative bands of three independent experiments are presented. The density of the bands was quantified and normalized to that of $\beta$-actin. Quantification of (B) HMGB1, (C) TLR4, (D) IL-1 $\beta$, (E) IL-6 and (F) COX2 expression levels. Data are expressed as the mean \pm standard deviation $(\mathrm{n}=3)$. " $\mathrm{P}<0.05$ vs. the control group. ${ }^{*} \mathrm{P}<0.05$ vs. the TAK 242 group. ${ }^{+} \mathrm{P}<0.05$ vs. the DCD group. DCD, donors after circulatory death; HMGB1, high-mobility group box protein b1; TLR4, toll-like receptor 4; IL, interleukin; COX2, mitochondrially encoded cytochrome c oxidase II; TNF- $\alpha$, tumor necrosis factor- $\alpha$.

In the present study, SD rats were used to establish a model of DCD livers (23). The livers were preserved in cold UW solution for $24 \mathrm{~h}$ and then connected to a IPRL system for perfusion, so that tissue and perfusate were easily collected for assessing hepatic IRI. Although an in vitro IPRL system rather than an orthotopic liver transplantation model was applied to assess liver quality, the rat liver transplantation model closely resembles the physiological state and pathological condition of DCD livers. By reducing aminotransferase levels in the perfusate and alleviating mitochondrial damage and hepatic apoptosis, the present study demonstrated that TAK 242 has restorative effects against TLR4-associated inflammatory responses, and resultantly reduces mitochondrial component damage and hepatocyte necrosis in addition to improving hepatic function. 

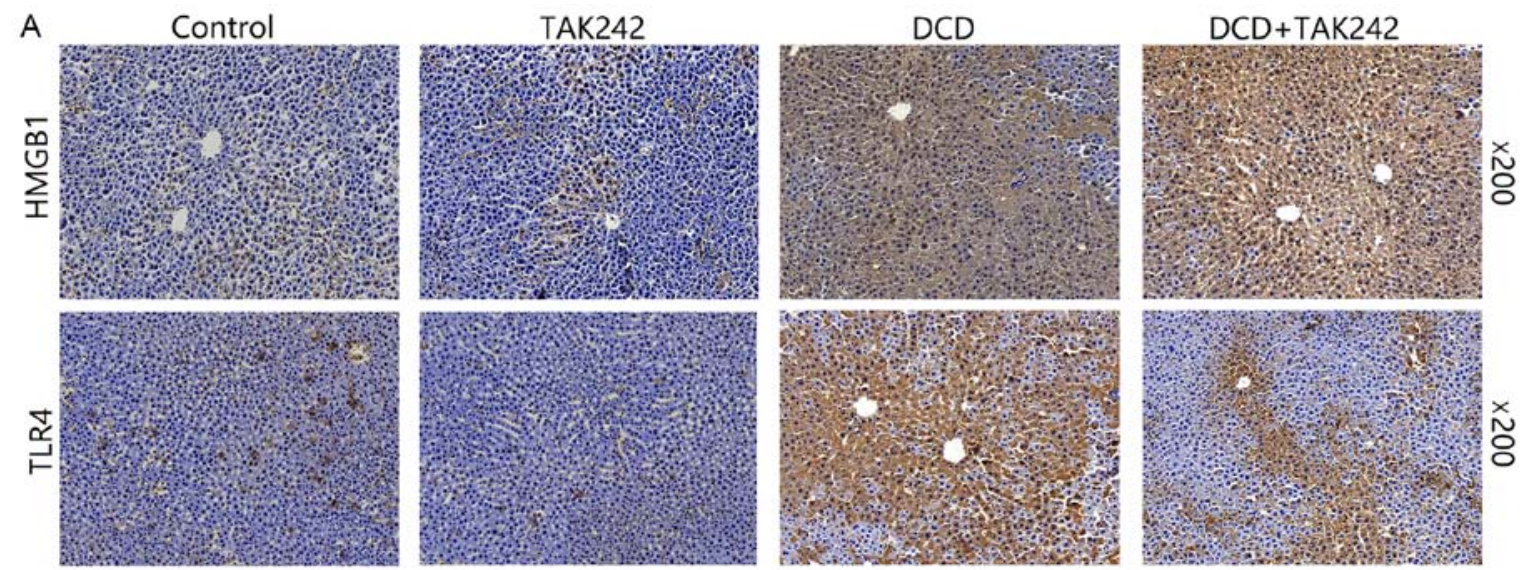

B

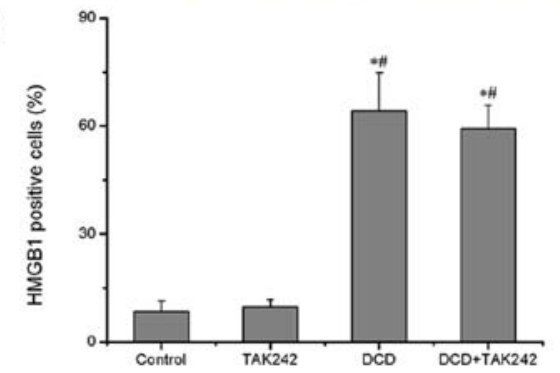

D

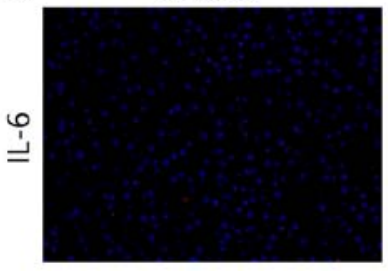

TAK242

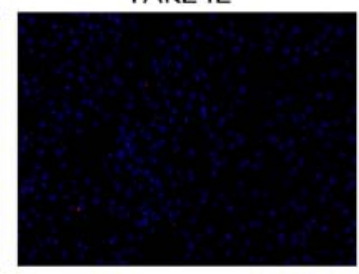

C

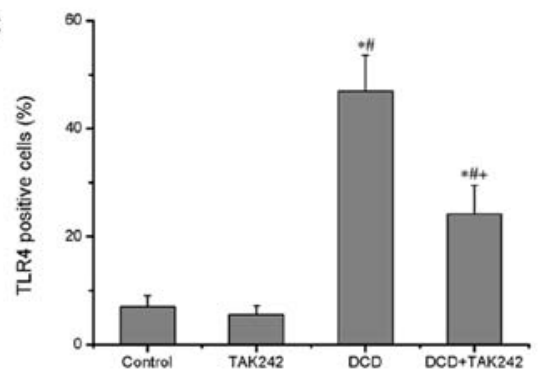

DCD

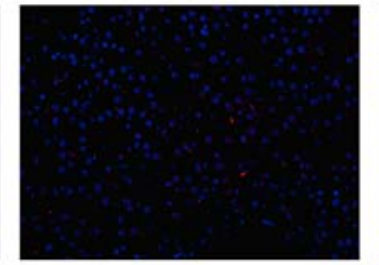

$D C D+T A K 242$

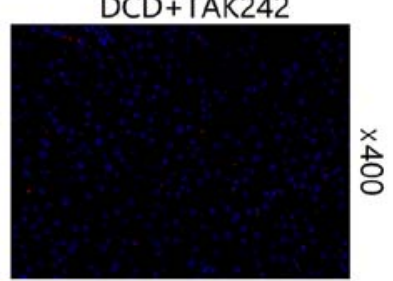

Figure 6. TAK242 pretreatment reduces the distribution of TLR4 and the release of IL-6. (A) Location of HMGB1 and TLR4 in the hepatic tissues are indicated by the brown regions. Magnification, x200. (B) HMGB1 positive cells (\%) in each group. (C) TLR4 positive cells (\%) in each group. (D) Immunofluorescence of IL-6. Magnification, $\mathrm{x} 400$. ${ }^{*} \mathrm{P}<0.05$ vs. the control group. ${ }^{\#} \mathrm{P}<0.05$ vs. the TAK 242 group. ${ }^{+} \mathrm{P}<0.05$ vs. the $\mathrm{DCD}$ group. $\mathrm{DCD}$, donors after circulatory death; TLR4, toll-like receptor 4; HMGB1, high-mobility group box protein b1; IL-6, interleukin-6.

Hepatic IRI is a complex pathological process in which tissue injury is initiated by ischemia and further aggravated by the recovery of blood perfusion, with mitochondrial dysfunctions that characterize hepatic IRI (32). During the ischemic process, mitochondria produce large amounts of ROS as a result of the damaged electron transport chain. With the recovery of the oxygen supply, more ROS are generated from oxidative damage to mitochondrial components $(29,32,33)$. The levels of MDA, a product of lipid peroxidation, usually reflect the degree of oxidative damage and indirectly mirror the degree of IRI. It was revealed that the increased levels of ROS and MDA in the DCD livers were significantly reduced by TAK242 $(\mathrm{P}<0.05)$. When mitochondria are severely damaged, they will fail to maintain their normal morphology, structure and function, resulting in an influx of extracellular macromolecules that contribute to mitochondrial swelling and crista disintegration (9). In the model used in the present study, the mitochondrial damage caused by hepatic IRI was clearly observed; however, it was significantly improved by pretreatment with TAK 242 $(\mathrm{P}<0.05)$. Damaged mitochondria release caspases and apoptosis-inducing factors and induce apoptosis $(9,34,35)$, a key mechanism used to maintain the balance of the intracellular environment. Previous studies have revealed that the excessive activation of apoptosis is highly associated with the poor prognosis of DCD livers (36,37). Hamada et al (38) revealed that matrix metalloproteinase (MMP)-9 activity may result in the detachment of hepatocytes from the extracellular matrix and apoptosis in hepatic IRI. One recent study has revealed that apoptosis is also implicated in postoperative complications in liver transplantation (39). The present study therefore determined DNA fragmentation as a hallmark of apoptosis in the DCD livers and identified that TAK242 pretreatment substantially reduces oxidative damage and the apoptosis rate of hepatocytes. Liver fibrosis may be associated with the repair process following liver ischemia reperfusion injury (40). The formation of liver fibrosis takes a number of weeks $(41,42)$, however, the livers were perfused for $1 \mathrm{~h}$ in the present study, and the quality of the livers were determined according to the necrosis and apoptosis of the tissue. In future experiments, the association between MMP-2/-9, cathepsins $\mathrm{S} / \mathrm{K}$, liver fibrosis and liver ischemia reperfusion injury will be assessed via a rat liver transplantation model.

TLRs are present on innate immune cells in which they trigger an innate immune response against pathogens $(43,44)$. In livers, TLRs are mainly expressed on the sinusoidal endothelial cells and hepatocytes $(30,43)$. TLR4 has been 
identified to have a crucial function in the activation of the innate immune response and contribute to the pathogenesis of sepsis (44). TLR4 also regulates inflammation through cathepsins (45). Endogenous ligands, including HMGB1 and heat shock proteins, activate the aseptic inflammatory response by binding to TLR4 in IRI (46). HMGB1 translocates from the nucleus to the cytoplasm and is then released to the extracellular space when hepatocytes are exposed to ischemic and hypoxic conditions (47). Upon binding to TLR4, extracellular HMGB1 serves as a danger signal that promotes the production of inflammatory mediators $(43,45)$, which amplify inflammatory signaling in a positive feedback loop $(48,49)$. In the present study, the increased production of cytokines, including IL-1 $\beta$, IL- 6 and TNF- $\alpha$, are involved in the inflammatory response and tissue injury. However, the beneficial effects of TAK242 were achieved, at least partially through the downregulation of IL-1 $\beta$, IL- 6 and TNF- $\alpha$. With regard to the irresponsive nature of HMGB1 to TAK242 pretreatment, one potential explanation is that TAK 242 exerts an inhibitory effect on TLR4 activation and its downstream signaling pathway, but not on TLR4 activators, including HMGB1 $(50,51)$.

In summary, the present study demonstrated that the TLR4 signaling pathway serves a pivotal function in the hepatic IRI of DCD, promoting the inflammatory cascade and deteriorating hepatic injury. Furthermore, pretreatment with TAK242 of DCD livers effectively reduces circulatory death-induced hepatic injury and decreases inflammatory responses via inhibiting TLR4-mediated signaling. Therefore, targeting TLR4 signaling may help to ameliorate hepatic IRI and improve organ function following liver transplantation. Thus, the results of the present study provide novel insight into the treatment of hepatic IRI from DCD organ donors.

\section{Acknowledgements}

The authors would like to thank Miss Pei Zhang and Miss Anna Du from The Department of Core Facility and Technical Support (Wuhan Institute of Virology), for their assistance with TEM micrographs.

\section{Funding}

The present study was supported by The Natural Science Foundation of Jiangxi Province (grant no. 20171BAB205010), The Education Department of Jiangxi Province (grant no. GJJ180014) and The National Natural Science Foundation of China (grant no. U1403222).

\section{Availability of data and materials}

The datasets used and/or analyzed during the present study are available from the corresponding author on reasonable request.

\section{Authors' contributions}

$\mathrm{XZ}$ and QX designed the experiment, established the rat models and performed liver perfusion, analyzed and interpreted data and drafted the manuscript. ZL and WW performed histological and molecular biological experiments, and interpreted data. CL, PY and WY performed molecular biological experiments and analyzed data. JX and QY designed and performed the experiment, and interpreted the data. All authors read and approved the final manuscript.

\section{Ethics approval and consent to participate}

The present experiment was conducted with the ethical approval of The Animal Experimental Ethics Committee of Wuhan University and all experimental procedures were performed in accordance with The Guidance for The Care and Use of Laboratory Animals (19).

\section{Patient consent for publication}

Not applicable.

\section{Competing interests}

The authors declare that they have no competing interests.

\section{References}

1. Ortega-Deballon I, Hornby L and Shemie SD: Protocols for uncontrolled donation after circulatory death: A systematic review of international guidelines, practices and transplant outcomes. Crit Care 19: 268, 2015

2. Bendorf A, Kelly PJ, Kerridge IH, McCaughan GW, Myerson B, Stewart $\mathrm{C}$ and Pussell BA: An international comparison of the effect of policy shifts to organ donation following cardiocirculatory death (DCD) on donation rates after brain death (DBD) and transplantation rates. PLoS One 8: e62010, 2013.

3. Jay C, Ladner D, Wang E, Lyuksemburg V, Kang R, Chang Y, Feinglass J, Holl JL, Abecassis M and Skaro AI: A comprehensive risk assessment of mortality following donation after cardiac death liver transplant-an analysis of the national registry. J Hepatol 55: 808-813, 2011.

4. Dageforde LA, Feurer ID, Pinson CW and Moore DE: Is liver transplantation using organs donated after cardiac death cost-effective or does it decrease waitlist death by increasing recipient death? HPB (Oxford) 15: 182-189, 2013.

5. Nastos C, Kalimeris K, Papoutsidakis N, Tasoulis MK, Lykoudis PM, Theodoraki K, Nastou D, Smyrniotis V and Arkadopoulos N: Global consequences of liver ischemia/reperfusion injury. Oxid Med Cell Longev 2014: 906965, 2014.

6. Zhai Y, Petrowsky H, Hong JC, Busuttil RW and Kupiec-Weglinski JW: Ischaemia-reperfusion injury in liver transplantation-from bench to bedside. Nat Rev Gastroenterol Hepatol 10: 79-89, 2013.

7. Zhai Y, Busuttil RW and Kupiec-Weglinski JW: Liver ischemia and reperfusion injury: New insights into mechanisms of innate-adaptive immune-mediated tissue inflammation. Am J Transplant 11: 1563-1569, 2011.

8. Deoliveira ML, Jassem W, Valente R, Khorsandi SE, Santori G, Prachalias A, Srinivasan P, Rela M and Heaton N: Biliary complications after liver transplantation using grafts from donors after cardiac death: Results from a matched control study in a single large volume center. Ann Surg 254: 716-723, 2011.

9. Zorov DB, Juhaszova M and Sollott SJ: Mitochondrial reactive oxygen species (ROS) and ROS-induced ROS release. Physiol Rev 94: 909-950, 2014.

10. Chouchani ET, Pell VR, Gaude E, Aksentijević D, Sundier SY, Robb EL, Logan A, Nadtochiy SM, Ord ENJ, Smith AC, et al: Ischaemic accumulation of succinate controls reperfusion injury through mitochondrial ROS. Nature 515: 431-435, 2014.

11. Szabo G and Petrasek J: Inflammasome activation and function in liver disease. Nat Rev Gastroenterol Hepatol 12: 387-400, 2015.

12. Quesnelle KM, Bystrom PV and Toledo-Pereyra LH: Molecular responses to ischemia and reperfusion in the liver. Arch Toxicol 89: 651-657, 2015.

13. Lu L, Zhou H, Ni M, Wang X, Busuttil R, Kupiec-Weglinski J and Zhai Y: Innate immune regulations and liver ischemia reperfusion injury. Transplantation 100: 2601-2610, 2016. 
14. Theodoraki K, Karmaniolou I, Tympa A, Tasoulis MK, Nastos C, Vassiliou I, Arkadopoulos N and Smyrniotis V: Beyond preconditioning: Postconditioning as an alternative technique in the prevention of liver ischemia-reperfusion injury. Oxid Med Cell Longev 2016: 8235921, 2016.

15. Bejaoui M, Pantazi E, Folch-Puy E, Baptista PM, García-Gil A, Adam R and Roselló-Catafau J: Emerging concepts in liver graft preservation. World J Gastroenterol 21: 396-407, 2015.

16. Radojkovic M, Stojanovic M, Stanojevic G, Radojkovic D, Gligorijevic J, Ilic I and Stojanovic N: Ischemic preconditioning vs adenosine vs prostaglandin E1 for protection against liver ischemia/reperfusion injury. Brazilian J Med Biol Res 50: e6185, 2017.

17. Mergental H, Perera MT, Laing RW, Muiesan P, Isaac JR, Smith A, Stephenson BT, Cilliers H, Neil DA, Hübscher SG, et al: Transplantation of declined liver allografts following normothermic ex-situ evaluation. Am J Transplant 16: 3235-3245, 2016

18. Sha T, Sunamoto M, Kitazaki T, Sato J, Ii M and Iizawa Y: Therapeutic effects of TAK-242, a novel selective Toll-like receptor 4 signal transduction inhibitor, in mouse endotoxin shock model. Eur J Pharmacol 571: 231-239, 2007.

19. Li M, Wang ZN, Yang LF, Yan Y, Cai LM, Li YT, Qiao YK and Chen ZG: TLR4 antagonist suppresses airway remodeling in asthma by inhibiting the T-helper 2 response. Exp Ther Med 14: 2911-2916, 2017.

20. Committee for the Update of the Guide for the care and use of Laboratory Animals, Institute for Laboratory Animal Research, Division on Earth and Life Studies, et al: Guide For the care and use of laboratory animals eighth edition [EB/OL]

21. Zhao Y, Zhao Y, Zhang M, Zhao J, Ma X, Huang T, Pang H, Li J and Song J: Inhibition of TLR4 signalling-induced inflammation attenuates secondary injury after diffuse axonal injury in rats Mediators Inflamm 2016: 4706915, 2016.

22. Yokoi T, Yokoyama Y, Kokuryo T, Yamaguchi J and Nagino M: Inhibition of Toll-like receptor 4 ameliorates experimental postischemic injury in the cholestatic liver through inhibition of high-mobility group box protein b1 (HMGB1) signaling. Surgery 163: 270-276, 2018.

23. Schlegel A, Graf R, Clavien PA and Dutkowski P: Hypothermic oxygenated perfusion (HOPE) protects from biliary injury in a rodent model of DCD liver transplantation. J Hepatol 59: 984-991, 2013

24. Liu Z, Zhang X, Xiao Q, Ye S, Lai CH, Luo J, Huang X, Wang W, Zeng $\mathrm{C}$, Zhong Z, et al: Pretreatment donors after circulatory death with simvastatin alleviates liver ischemia reperfusion injury through a KLF2-dependent mechanism in rat. Oxid Med Cell Longev 2017: 3861914, 2017.

25. Suzuki S, Toledo-Pereyra LH, Rodriguez FJ and Cejalvo D: Neutrophil infiltration as an important factor in liver ischemia and reperfusion injury. Modulating effects of FK506 and cyclosporine. Transplantation 55: 1265-1272, 1993.

26. Flameng W, Borgers $M$, Daenen $W$ and Stalpaert $G$ Ultrastructural and cytochemical correlates of myocardial protection by cardiac hypothermia in man. J Thorac Cardiovasc Surg 79: 413-424, 1980

27. Livak KJ and Schmittgen TD: Analysis of relative gene expression data using real-time quantitative PCR and the 2(-Delta Delta C(T)) method. Methods 25: 402-408, 2001.

28. Mateo R, Cho Y, Singh G, Stapfer M, Donovan J, Kahn J, Fong TL, Sher L, Jabbour N, Aswad S, et al: Risk factors for graft survival after liver transplantation from donation after cardiac death donors: An analysis of OPTN/UNOS data. Am J Transplant 6: 791-796, 2006.

29. Eltzschig HK and Eckle T: Ischemia and reperfusion-from mechanism to translation. Nat Med 17: 1391-401,2011.

30. Nace GW, Huang H, Klune JR, Eid RE, Rosborough BR, Korff S, Li S, Shapiro RA, Stolz DB, Sodhi CP, et al: Cellular specific role of toll-like receptor 4 in hepatic ischemia-reperfusion injury. Hepatology 58: 374-387, 2013

31. Takashima K, Matsunaga N, Yoshimatsu M, Hazeki K, Kaisho T, Uekata M, Hazeki O, Akira S, Iizawa Y and Ii M: Analysis of binding site for the novel small-molecule TLR4 signal transduction inhibitor TAK242 and its therapeutic effect on mouse sepsis model. Br J Pharmacol 157: 1250-1262, 2009.

32. Granger DN and Kvietys PR: Reperfusion injury and reactive oxygen species: The evolution of a concept. Redox Biol 6: $524-551,2015$
33. Kalogeris T, Baines CP, Krenz M and Korthuis RJ: Cell biology of ischemia/reperfusion injury. Int Rev Cell Mol Biol 298: 229-317, 2012.

34. Papanicolaou KN, Phillippo MM and Walsh K: Mitofusins and the mitochondrial permeability transition: The potential downside of mitochondrial fusion. Am J Physiol Heart Circ Physiol 303: H243-H255, 2012.

35. Baines CP and Molkentin JD: Adenine nucleotide translocaseinduces cardiomyocyte death through upregulation of the pro-apoptotic protein Bax. J Mol Cell Cardiol 46: 969-977, 2009.

36. Luedde T, Kaplowitz N and Schwabe RF: Cell death and cell death responses in liver disease: Mechanisms and clinical relevance. Gastroenterology 147: 765-783.e4, 2014.

37. Chen L, Ren F, Zhang H, Wen T, Piao Z, Zhou L, Zheng S, Zhang J, Chen Y, Han Y, et al: Inhibition of glycogen synthase kinase $3 \beta$ ameliorates D-GalN/LPS-induced liver injury by reducing endoplasmic reticulum stress-triggered apoptosis. PLoS One 7: e45202, 2012.

38. Hamada T, Duarte S, Tsuchihashi S, Busuttil RW and Coito AJ: Inducible nitric oxide synthase deficiency impairs matrix metalloproteinase-9 activity and disrupts leukocyte migration in hepatic ischemia/reperfusion injury. Am J Pathol 174: 2265-2277, 2009.

39. Tian Y, Wang J, Wang W, Ding Y, Sun Z, Zhang Q, Wang Y, Xie H, Yan S and Zheng S: Mesenchymal stem cells improve mouse non-heart-beating liver graft survival by inhibiting Kupffer cell apoptosis via TLR4-ERK1/2-Fas/FasL-caspase3 pathway regulation. Stem Cell Res Ther 7: 157, 2016.

40. Konishi T, Schuster RM and Lentsch AB: Liver repair and regeneration after ischemia-reperfusion injury is associated with prolonged fibrosis. Am J Physiol Gastrointest Liver Physiol 316 G323-G331, 2019.

41. Marrone G, Shah VH and Gracia-Sancho J: Sinusoidal communication in liver fibrosis and regeneration. J Hepatol 65: 608-617, 2016.

42. Barton GM and Kagan JC: A cell biological view of Toll-like receptor function: Regulation through compartmentalization. Nat Rev Immunol 9: 535-542, 2009.

43. Zhai Y, Shen XD, O'Connell R, Gao F, Lassman C, Busuttil RW, Cheng $\mathrm{G}$ and Kupiec-Weglinski JW: Cutting edge: TLR4 activation mediates liver ischemia/reperfusion inflammatory response via ifn regulatory factor 3-dependent MyD88-independent pathway. J Immunol 12: 7115-7119, 2004.

44. Wittebole X, Castanares-Zapatero D and Laterre PF: Toll-like receptor 4 modulation as a strategy to treat sepsis. Mediators Inflamm 2010: 568396, 2010.

45. de Mingo Á, de Gregorio E, Moles A, Tarrats N, Tutusaus A, Colell A, Fernandez-Checa JC, Morales A and Marí M: Cysteine cathepsins control hepatic NF- $\kappa$ B-dependent inflammation via sirtuin-1 regulation. Cell Death Dis 7: e2464, 2016.

46. Tsung A, Klune JR, Zhang X, Jeyabalan G, Cao Z, Peng X, Stolz DB, Geller DA, Rosengart MR and Billiar TR: HMGB1 release induced by liver ischemia involves Toll-like receptor 4-dependent reactive oxygen species production and calcium-mediated signaling. J Exp Med 204: 2913-2923, 2007.

47. Zhao G, Fu C, Wang L, Zhu L, Yan Y, Xiang Y, Zheng F, Gong F, Chen $S$ and Chen G: Down-regulation of nuclear HMGB1 reduces ischemia-induced HMGB1 translocation and release and protects against liver ischemia-reperfusion injury. Sci Rep 7: 46272, 2017.

48. Zhang GY, Lu D, Duan SF, Gao YR, Liu SY, Hong Y, Dong PZ, Chen YG, Li T, Wang DY, et al: Hydrogen Sulfide alleviates lipopolysaccharide-induced diaphragm dysfunction in rats by reducing apoptosis and inflammation through ROS/MAPK and

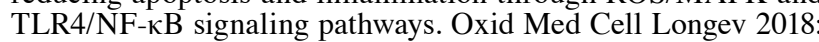
9647809, 2018

49. Wang L, Li N, Lin D and Zang Y: Curcumin protects against hepatic ischemia/reperfusion induced injury through inhibiting TLR4/NF- $\kappa B$ pathway. Oncotarget 8: 65414-65420, 2017.

50. Yu Y, Tang D and Kang R: Oxidative stress-mediated HMGB1 biology. Front Physiol 6: 93, 2015.

51. Yang H, Wang H, Chavan SS and Andersson U: High mobility group box protein 1 (HMGB1): The prototypical endogenous danger molecule. Mol Med 21 (Suppl): S6-S12, 2015.

This work is licensed under a Creative Commons Attribution-NonCommercial-NoDerivatives 4.0 International (CC BY-NC-ND 4.0) License. 